\title{
Migration and Economic Growth
}

\author{
edited by Mathias Czaika and Carlos Vargas-Silva \\ Cheltenham: Edward Elgar 2012 \\ ISBN 978-1-78100-353-4 \\ Hardcover, \$465, 843+xxvi pp.
}

\author{
Reviewed by Bill Marr \\ Wilfrid Laurier University (Waterloo ON)
}

\begin{abstract}
Mathias Czaika and Carlos Vargas-Silva have assembled an excellent collection of previously published articles on all aspects of the connection between migration of people and economic growth. As well, they provide an introduction that sets out the cross-connections between migration and economic growth, and provides a lead-in to the articles that follow in their compilation. They recognize that the relationship between migration and economic growth is complex; to paraphrase the editors, that relationship is multi-level, multi-dimensional, dynamic, and endogenous.

The forty previously published articles are mostly classics in their area of study, and range from the theoretical to the empirical, with some articles of course adding to both our theoretical and empirical knowledge in the areas of migration and economic growth. The articles are organized under four parts or themes, each one emphasizing some aspect of the interconnection between migration and economic growth. Part I contains articles that examine, both at the theoretical and the empirical levels, how economic growth and other economic factors have driven migration: What influence has economic growth in particular had on migration? Part II contains articles that reverse the causal direction and ask: What effects has immigration had on economic growth? Articles on three sub-impacts are included: labour markets, fiscal impact, and technology and innovation. Part III reprises articles that deal with the effects that emigration has on economic growth, emphasizing two topics - namely, the brain drain-brain gain and remittances. The articles in Part IV take a longer-term perspective and ask what role, if any, migration has played in bringing about a convergence in wages and incomes across countries and regions, and even within countries.

There is not much more that needs to be said about a collection of forty previously published articles. They all appeared originally in very good journals, and thus have been critically reviewed. Other editors would no doubt have selected some additional articles, but those that are included here would be an excellent place to start if one wanted to cover most of the important topics and researched areas in the overlap between migration and economic growth during the last fifty years.
\end{abstract}

